\title{
Variações ecológicas, fitofisionômicas, edáficas e distribuição das espécies em um gradiente ambiental entre campinarana e campina - Bacia do Rio Demini, AM
}

Species distribution, ecological, phytophysionomic and edaphic changes in an environmental gradient between campinarana and campina - Demini River Basin, $A M$

Felipe Silva Guimarães Doutorando em Geografia pela Pontifícia Universidade Católica de Minas Gerais Bolsista de doutorado na Pontifícia Universidade Católica de Minas Gerais felipeecologia@yahoo.com.br

Guilherme Taitson Bueno Doutor em Geografia Pela Universidade Estadual Paulista Júlio de Mesquita Filho Docente na Universidade Federal de Goiás guilhermetaitsonb@gmail.com

Débora de Sena Oliveira Mendes Mestre em geografia pela Pontificia Universidade Católica de Minas Gerais Graduanda em geografia na Universidade Federal de Minas Gerais eco.debora@yahoo.com.br

Alisson Duarte Diniz Doutor em Geografia Pela pela Universidade Estadual Paulista Júlio de Mesquita Filho Docente na Universidade Federal da Bahia alisson.diniz@ufba.br

Jorge Batista de Souza Doutorando em Geografia pela Pontifícia Universidade Católica de Minas Gerais Docente na Pontificia Universidade Católica de Minas Gerais jorgebsouza@yahoo.com.br

\begin{abstract}
Resumo
Campinas e campinaranas são fitofisionomias amazônicas ocorrentes, sobretudo, na bacia do Rio Negro. Há poucos estudos sobre a composição florística e origem destas fitofisionomias. Trabalhos que buscam relacionar a distribuição geográfica das espécies e fitofisionomias com variáveis edáficas são ainda mais raros. Os objetivos deste trabalho foram: realizar estudo fitossociológico em uma área que apresenta transições entre campinarana florestada, arborizada e campina; esclarecer as relações entre variáveis edáficas e a vegetação ao longo de um gradiente ecológico que perpassa por essas fitofisionomias. A área de estudo está localizada na região centro leste do município de Barcelos. Ao longo de um trasecto foram abertas trincheiras para análise pedológica e montadas parcelas para amostragem vegetação. Amostras de solo também foram coletadas no centro de cada parcela. Para analizar as relações entre as variáveis edáficas e bióticas foram utilizadas as análises PCA, CCA e um perfil geoecológico. Os resultados sugerem que a flora da região parece ser originada principalmente do planalto das Guianas, algumas espécies podem ter origem das florestas de terra firme. Houve mudança expressiva da composição florística, entre outros aspéctos ecológicos, ao longo do transecto. As variáveis ambientais mais relacionadas a estas mudanças são o nível do lençol freático e granulometria.
\end{abstract}

Palavras-chave: Amazônia; Fitogeografia; Ecologia de vegetação. 


\begin{abstract}
Campinas and campinaranas are Amazon phytophysiognomies occurring mainly in the Rio Negro basin. There are a few studies about the floristic composition and origin of these vegetation types. Works that seek to relate the geographical distribution of species and vegetation types with soil variables are even rarer. This work has the following goals: to perform a phytosociological study in an area which has transitions between forested campinarana, wooded campinarana and campina; point the relationships between soil and vegetation characteristics along an ecological gradient that permeates these vegetation types. The study area is located in the center-eastern region of the Barcelos municipality. Soil samples were also collected in each parcel center. To analyze the relationship between soil and biotic variables were used the PCA and CCA analysis besides the geoecologic profile. The results suggest the flora of the region seems to be originated mainly from Guyana highlands and some species may originate from terra firme forests. There was a significant change in floristic composition and other environmental aspects over the ransect. The variables most related to these changes are the groundwater level and particle size.
\end{abstract}

Keywords: Amazon; phytogeography; vegetation ecology.

\title{
1. INTRODUÇÃO
}

As campinas são fitofisionomias abertas normalmente com uma matriz herbácea onde podem ocorrer arbustos isolados variando entre 1 a $5 \mathrm{~m}$, com alguns indivíduos atingindo a $9 \mathrm{~m}$ (FERREIRA, 2009) enquanto as campinaranas são fitofisionomias florestais caracterizadas por apresentar sub-bosque relativamente aberto e escassez de cipós e lianas, com indivíduos arbóreos podendo atingir $30 \mathrm{~m}$ (ANDERSON, 1981). Ambas são ecossistemas amazônicos, normalmente sujeitos ao alagamento periódico decorrente da flutuação do nível do lençol freático, cuja vegetação apresenta elevada esclerofilia (SILVEIRA, 2003), baixa produtividade, baixa diversidade e solos extremamente oligotróficos quando comparados às florestas de terra firme (ANDERSON 1981; SILVEIRA 2003; VICENTINI 2004).

Velozo et al. (1991), subdivide as formações sobre areia branca da Amazônia em três subgrupos: campinarana florestada, campinarana arborizada e campinarana lenhosa. Ferreira (2009) dá ao termo campina uma definição mais robusta que é similar ao conceito de campinarana lenhosa proposto por Velozo et al. (1991). Neste trabalho optou-se por utilizar o conceito de campina apresentado por Ferreira (2009) para designar formações abertas que se enquadram nesta definição. Para as formações de porte florestal foram utilizados os conceitos de campinarana florestada e campinarana arborizada apresentados por Veloso et al. (1991).

As campinas e campinaranas ocorrem, frequentemente, em padrão insular, cercadas por uma matriz de floresta de terra firme, embora na bacia do Rio Negro e na região centro-sul de Roraima seja comum a ocorrência destes fitofisionomias em padrões mais contínuos (ANDERSON,1978; WHITMORE; PRANCE, 1987; JUNK et al. 2011). Quanto ao contexto pedológico, estão 
associadas, principalmente, a Espodossolos (KUBITZKI, 1990; NASCIMENTO et al; 2004; BUENO, 2009; FERREIRA, 2009; MENDONÇA, 2011) e a Neossolos Quartzarênicos (VALE, 2011; MENDONÇA, 2011).

É comum ocorrer uma transição gradativa, ou às vezes abrupta, entre as fisionomias de campina e campinarana (SILVEIRA, 2003). Estas transições são caracterizadas pela mudança na composição e estrutura da vegetação e comumente são determinadas por variações edáficas, como alterações de textura e fertilidade no solo (WORBES 1997; SILVEIRA, 2003; VALE, 2011; MENDONÇA, 2011), do nível do lençol freático e tempo de alagamento ocasionado pela elevação deste (COOMES; GRUBB, 1996; DALY ; MITCHELL 2000; SILVEIRA 2003; VICENTINI, 2004; JUNK et al., 2011).

Estudos têm mostrado que a flora das campinas e campinaranas é formada principalmente por espécies que migraram de outros ecossistemas ou regiões, como do Escudo das Guianas (FERREIRA, 2009), dos igapós (ANDERSON, 1978; KUBTIZKI, 1987), das Florestas de Terra Firme (STROPP et al., 2011) e, em proporção bem menor, dos cerrados (FERREIRA, 2009). Segundo Stropp (2011), as condições de estresse, tanto hídrico quanto nutricional destes ambientes, funcionam como filtro para as espécies que tentam colonizá-los. Assim, as espécies que compõem estas comunidades são normalmente dotadas de adaptações morfológicas, fisiológicas que as permitem colonizar tais ambientes.

Estudos sobre as campinas e campinaranas da Amazônia são incipientes e esparsos (ANDERSON, 1981). Segundo Ferreira (2009), Mendonça (2011) e Vicentini (2004), por causa da escassez destes estudos, e concentração deles próximo a Manaus, pouco se sabe sobre estes ecossistemas. Para Vicentini (2011), a distribuição insular e o elevado nível de endemismos são fatores que contribuem para que muitas espécies novas sejam encontradas. Estudos de cunho biogeográfico que propõem elucidar as relações entre as características edáficas e características da vegetação, bem como estrutura, composição e distribuição de espécies e fitofisionomias também são raros nas campinas e campinaranas. Na região do Rio Demini, dados botânicos e pedológicos sobre estes ecossistemas são ainda mais escassos se comparados a várias outras regiões da Amazônia. Nesse contexto, o presente estudo apresenta-se como um dos esforços iniciais no sentido de melhor conhecer as características da vegetação da região e as influências de varáveis edáficas sobre a distribuição das espécies e fitofisionomias.

Os objetivos deste trabalho são: 1 realizar um estudo fitossociológico em uma área que apresenta transições entre campinarana florestada, arborizada e campina; 2. Esclarecer as relações entre variáveis edáficas e a vegetação, considerando a físionomia, composição e estrutura ao longo de um gradiente edáfico ecológico que perpassa por essas fitofisionomias. 


\section{METODOLOGIA}

\subsection{Caracterização da área de estudo}

A área de estudo está localizada na região centro leste do município de Barcelos - AM, à distância de $140 \mathrm{~km}$ ao norte da sede do referido município, na margem direita do rio Demini (figura 1). O clima da área de estudo é do tipo Afi, segudo a classificação de Köppen, com baixas variações na precipitação e na temperatura, sendo que a amplitude mensal desta última não ultrapassa $5^{\circ} \mathrm{C}$. A temperatura e a precipitação média anual são de $26^{\circ} \mathrm{C}$ e $2100 \mathrm{~mm}$, respectivamente (BRASIL, 1969) com as chuvas mais concentradas entre os meses de março e julho, atingindo maior precipitação $(300 \mathrm{~mm})$ em maio. Entre agosto e dezembro a precipitação varia de 120 a 135 mm (BRASIL, 1975). Quanto à Geologia, a área de estudo está localizada sobre Formação Içá (idade Terciária), caracterizada por ser uma sucessão sedimentar predominantemente psamítica que encerra subordinados níveis pelíticos (CPRM, 2005). Esta se encontra sobreposta à associação petrotectônica proterozóica do Complexo Cauaburi (BRASIL, 1975; CPRM, 2005). A área de estudo é uma extensa superfície sedimentar onde os baixos platôs, que constituem os interflúvios dos rios principais, estão entre 10 e $15 \mathrm{~m}$ acima do nível destes rios. $\mathrm{O}$ transecto estudado parte da margem direita do Rio Demini, sobre o baixo platô, atravessa a franja com solos de melhor drenagem e termina na zona alagada, interfluvial. Contempla, nessa sequência, as fitofisionomias de campinarana florestada, campinarana arborizada e campina.

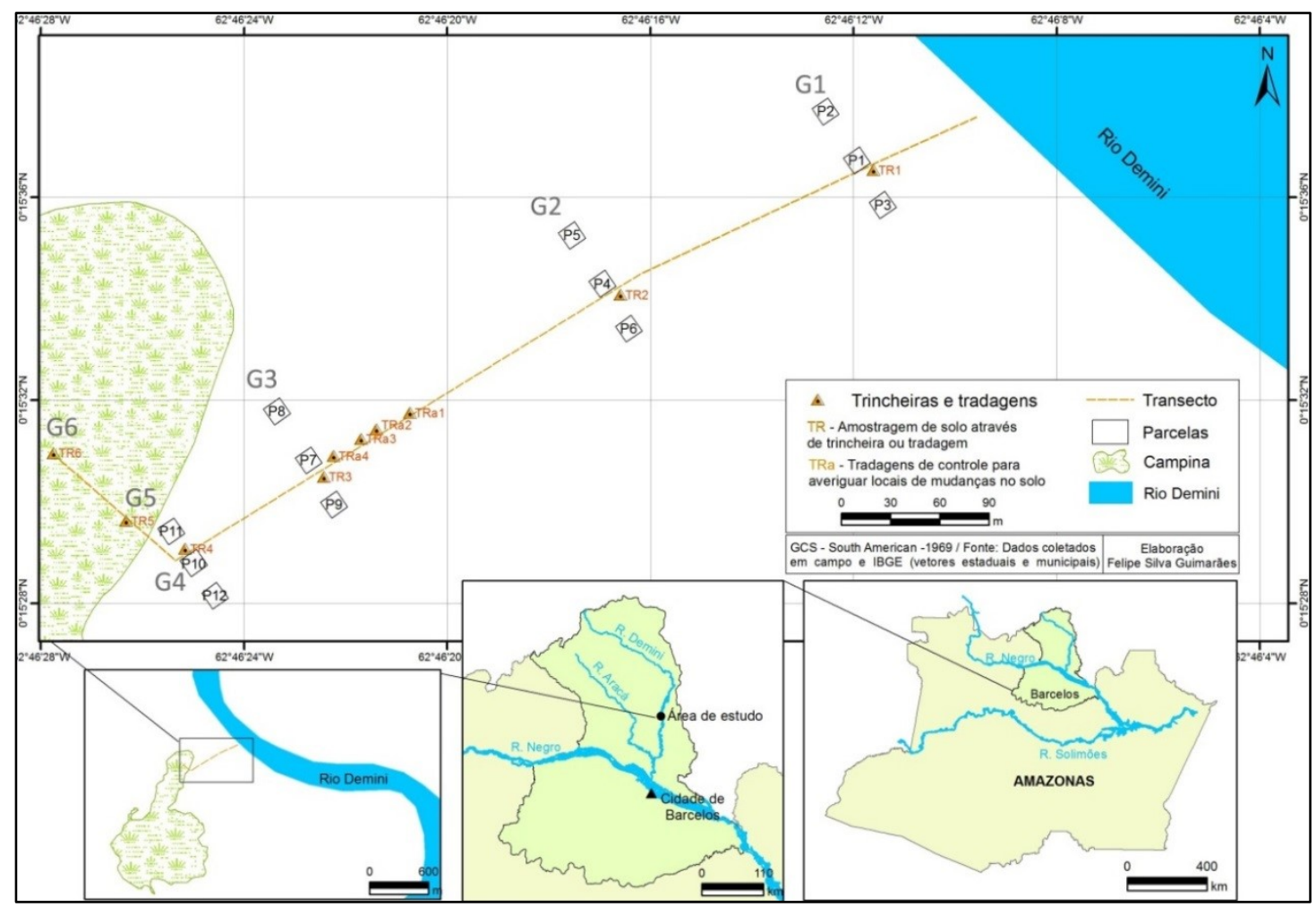

Figura 1: Localização da área de estudo, distribuição das parcelas ao longo do transecto e localização das trincheiras e tradagem. 


\subsection{Amostragem, identificação e análises laboratoriais}

Foi traçado um transecto que contemplou variações fisionômicas e estruturais da vegetação, características do solo e do nível do lençol freático. Com base nas variações de tais características, foram delimitados seis geoambientes ao longo do transecto: três na campinarana florestada (G1, G2 e G3), um na campinarana arborizada (G4) e dois na campina (G5 e G6). Posteriormente, foram montadas três parcelas de $10 \times 10 \mathrm{~m}$ em cada geoambiente, exceto em G5 e G6, totalizando 12 parcelas (figura 1). Todos os indivíduos com Perímetro à Altura do Peito (PAP) $\geq 20 \mathrm{~cm}$ tiveram a altura estimada com o auxílio de uma vara graduada, perímetro medido, material vegetativo e reprodutivo, quando presente, coletados. O material coletado foi encaminhado ao herbário do Instituto Nacional de Pesquisas da Amazônia (INPA) para identificação através de comparação com exsicatas. As amostras foram identificadas até o nível de espécie, quando possível. Em algumas espécies chegou-se apenas ao nível de gênero. As amostras não identificadas foram denominadas "morfo-espécie" com um número como sufixo para diferenciá-las.

A topografia do transecto foi levantada com a utilização de clinômetro. Para amostragem, descrição dos solos e observação do nível do lençol freático foram abertas três trincheiras ao longo do transecto. Estas foram posicionadas ao lado da parcela central dos geoambientes G1, G2 e G3, conforme mostra a figura 1. A descrição morfológica dos solos foi feita de acordo com Santos et al., (2005). Em G4, G5 e G6 a amostragem de solo foi feita apenas com o auxílio de um trado holandês, pois o elevado nível do lençol freático impossibilitou a abertura de trincheiras. No centro de cada parcela foram coletadas amostras de horizontes superficiais, inclusive serrapilheira, na profundidade de 0 - $20 \mathrm{~cm}$. Estas amostras foram encaminhadas para o laboratório de análise de solos da Universidade Federal de Viçosa (UFV) onde foram feitas as seguintes análises: $\mathrm{pH}$ em $\mathrm{H}_{2} \mathrm{O}, \mathrm{P}, \mathrm{K}$, $\mathrm{Na}, \mathrm{Ca}^{2+}, \mathrm{Mg}^{2+}, \mathrm{Al}^{3+}, \mathrm{H}+\mathrm{Al}$, teor de matéria orgânica (MO), P-remanescente (P-rem) e cálculo de capacidade de troca catiônica (CTC) e granulometria. Os solos foram classificados de acordo com o Sistema Brasileiro de Classificação de Solos (Embrapa, 2013).

Ressalta-se que devido, à alta densidade, pequeno diâmetro e altura dos indivíduos, estes não foram medidos nem contabilizados nos geoambientes da campina (G5 e G6). Consequentemente, não foi feito tratamento estatístico para esta fitofisionomia. No entanto, foi feito um caminhamento nestes geoambientes para a realização de uma caracterização florística e fisionômica. Nessa oportunidade, coletou-se amostras de ao menos um indivíduo de cada espécie encontrada. Também foram coletadas amostras de solo na profundidade de $0-20 \mathrm{~cm}$. Uma coleta foi realizada mais próxima ao limite com a campinarana arbórea (G5) e outra em local mais central da campina (G6), conforme mostra a figura 1 . 


\subsection{Tratamento dos dados}

Foram calculados os parâmetros fitossociológicos (Densidade Absoluta, Densidade Relativa, Freqüência Absoluta, Freqüência Relativa, Dominância Absoluta, Dominância Relativa e Índice de valor de Importância) para toda a área e também, separadamente, para cada geoambiente, conforme Muller-Dombois ; Ellenberg (1974). Também foi calculado o índice de diversidade de Shannon Wiener $\left(\mathrm{H}^{\prime}\right)$ para a área total e, separadamente, para cada geoambiente. A similaridade florística entre as unidades amostrais foi calculada através do índice Sörensen (CCS) e, posteriormente, com o auxílio do software PAST 3.0, foi elaborado um dendrograma, utilizando o método Ward, para melhor visualizar a similaridade entre as parcelas.

Para verificar a correlação entre as variáveis físico-químicas do solo e a distribuição das espécies ao longo do gradiente edáfico, foi utilizada a análise de correspondência canônica (CCA). Tal análise foi feita através do software Fitopac2. A CCA é a análise multivariada de ordenação atualmente mais aplicada ao estudo da vegetação (FELFILI et al., 2011). Esta técnica possibilita a ordenação de espécies de acordo com variáveis ambientais, a visualização da distribuição destas espécies ao longo de um gradiente edáfico, além de permitir a observação de padrões de variação da comunidade (TER BRAAK, 1986; TER BRAAK, 1987).

A entrada de dados para a realização da CCA é feita através de duas matrizes, sendo uma das variáveis preditoras (variáveis ambientais) e outra das variáveis resposta (espécies) (VALENTIN, 2012; FELFILI et al., 2011). No entanto, a utilização dos dados brutos na CCA pode gerar resíduos e pesos indesejados (LEGENDRE; GALLAGHER, 2001). Portanto, é recomendado que se faça tratamentos em ambas matrizes.

Antes de executar a CCA foi realizada uma análise de componentes principais (PCA), utilizando a matriz de variáveis preditores. Para a realização da PCA os valores destas variáveis foram normalizados utilizando o software Fitopac2, como é recomendado por Felfili et al. (2011), a fim de evitar que variáveis em unidades diferentes apresentem pesos distintos na análise. A utilização da PCA teve as seguintes finalidades: 1. verificar relações positivas e negativas entre as variáveis ambientais; 2. ordenar as unidades amostrais (parcelas) e as variáveis ambientais em um gráfico biplot que permite melhor visualização das relações positivas e negativas entre as unidades amostrais e variáveis ambientais; 3. averiguar a importância de cada uma das variáveis para a explicação do modelo, o que viabiliza a retirada de variáveis pouco explicativas (FELFILI et al., 2011) antes da execução da CCA; 4. verificar a colinearidade entre as variáveis ambientais possibilitando, assim, a redução do número de variáveis antes da utilização da CCA, diminuindo a redundância do modelo, conforme é recomendado por Felfili et al. (2011). 
Após verificar a colinearidade das variáveis ambientais, com o auxílio da PCA, estas foram separadas em grupos segundo o critério de colinearidade. Paralelamente, foi realizada uma análise canônica (CA) na matriz de espécies, também utilizando o software Fitopac2. Posteriormente, os scores do primeiro eixo das unidades amostrais foram transferidos para o software PAST juntamente com os valores dos grupos de variáveis ambientais colineares. Para cada grupo de variáveis colineares foi gerada uma matriz de correlação entre o eixo 1 e estas variáveis. Assim, as variáveis ambientais a serem utilizadas na CCA foram selecionadas com base nos seguintes critérios: 1. Colinearidade, verificada através da PCA; 2. Relação com o primeiro eixo da PCA; 3. Maior valor na matriz de correlação entre a variável e o primeiro eixo da $\mathrm{CA} ; 4$. Conceitos acerca das variáveis do solo, por exemplo, sabe-se que a CTC controla a concentração de H + Al (KIEHL, 1979), e não o contrário, portanto a CTC neste caso é mais importante.

Segundo Legendre e Gallagher (2001), uma grande quantidade de "zeros" na matriz, ocasionada pela ocorrência de espécies raras, pode produzir resultados não condizentes com a realidade quando são tratadas por técnicas multivariadas de ordenação, uma vez que superestimam o valor de tais espécies nas análises. $\mathrm{Na}$ matriz de variáveis resposta foram feitos os seguintes tratamentos conforme o sugerido por Legendre e Gallagher (2001), afim de evitar este problema: inicialmente foram excluídas da matriz as espécies raras, sendo consideradas raras espécies que ocorreram apenas uma vez em toda a amostragem. Posteriormente foi feita a transformação de Hellinger, utilizando o software R 3.0.2, na matriz de espécies (LEGENDRE; GALLAGHER, 2001). O fluxograma apresentado na figura 2 sintetiza o método utilizado para o tratamento dos dados antes da execução da CCA.

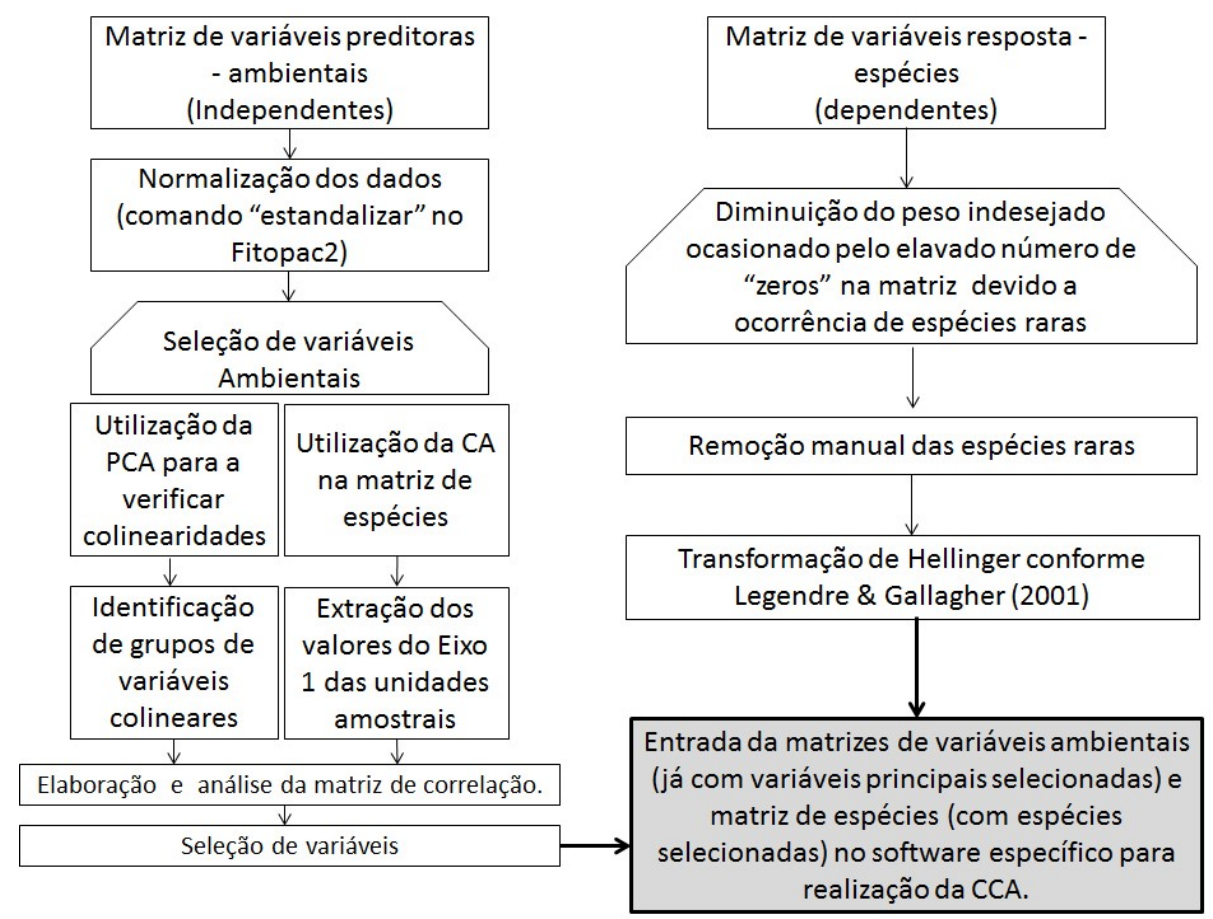

Figura 2: Fluxograma mostrando a sequência do tratamento de dados realizado antes da execução da análise de correspondência canônica (CCA). 


\subsection{Elaboração do perfil geoecólogico do transecto}

Com o intuito de melhor visualizar a relação entre as variáveis do solo e as características de vegetação ao longo do transecto estudado, foi elaborado um perfil geoecológico. Trata-se de uma técnica que permite a análise integrada das condições ambientais da paisagem (LEVIGHIN; VIADANA, 2003), a partir da qual é possível "representar cartograficamente secções de determinado espaço geográfico e fazer correlações entre os geo-elementos de interesse" (MEZZOMO et al., 2012).

O perfil geoecológico apresentado neste trabalho se difere dos perfis comumente encontrados na literatura (LEVIGHIN; VIADANA, 2003; MEZZOMO, 2008; MEZZOMO et al., 2012), pois estes últimos são representados a partir do alinhamento de variáveis ambientais, em maioria, de caráter qualitativo, como tipo de solo, litologia, tipo de vegetação entre outras. Neste trabalho, a maioria das variáveis utilizadas são de caráter quantitativo, portanto o perfil geoecológico foi confeccionado através do alinhamento de gráficos que representam características quantificáveis do solo e vegetação ao longo do transecto.

Para a elaboração do perfil geoecológico foram utilizados os dados de $\mathrm{K}, \mathrm{P}, \mathrm{Al}+\mathrm{H}, \mathrm{CTC}$, teor de matéria orgânica e granulometria, considerando os valores das análises de solo da profundidade de 0 a $20 \mathrm{~cm}$. Também foi adicionada uma linha apresentando a classificação dos solos. Quanto às características da vegetação, foram utilizados os dados que representam a variação das seguintes características ao longo do transecto: diversidade (índice de Shannon Wiener), altura média dos indivíduos, número de indivíduos mortos, número de indivíduos que apresentam ramificações no fuste abaixo da altura do PAP e densidade absoluta de indivíduos. Também foram representadas a topografia do transecto e a classificação da vegetação.

\section{RESULTADOS E DISCUSSÃO}

\subsection{Fitossociologia}

Foram encontradas 64 espécies distribuídas em 24 famílias. Destas, as que apresentaram maior número de espécies foram Lauraceae (9), Chrysobalanaceae (4), Fabaceae (4), Clusiaceae (4), Humiriaceae (3), Melastomataceae (3) e Myrtaceae (3) (Figura 3). As espécies com maior índice de valor de importância (IVI), considerando toda a área, foram Pagamea coriacea $(25,60)$, Humiria balsamifera $(22,5)$, Licania heteromorpha $(19,78)$ e Cybianthus fulvopuverulentus $(18,47)$. Os altos valores de Pagamea coriacea e Humiria balsamifera podem ser explicados pelas altas densidades, respectivamente 966,67 e 400,00 indivíduos/ha, e dominância, respectivamente 51,84\% e 22,28\%, destas espécies no último geoambiente (G4). Apenas uma espécie, Eugenia patrisii, ocorreu na 
metade das parcelas (frequência absoluta $=50 \%$ ). Esta espécie foi encontrada somente nas parcelas da campinarana florestada, onde o solo tem melhor drenagem e o lençol freático se encontrava distante da superfície. G5 e G6 (campina) foram caracterizados pala ocorrência de Hypolitrum schraderianum, formando uma matriz herbácea. G5 também apresentou espécies lenhosas com destaque para Myrcia guianensis e Pagamea coriacea. Muitas espécies foram encontradas em apenas um geoambiente, o que sugere preferências dos táxons por determinadas condições ambientais.

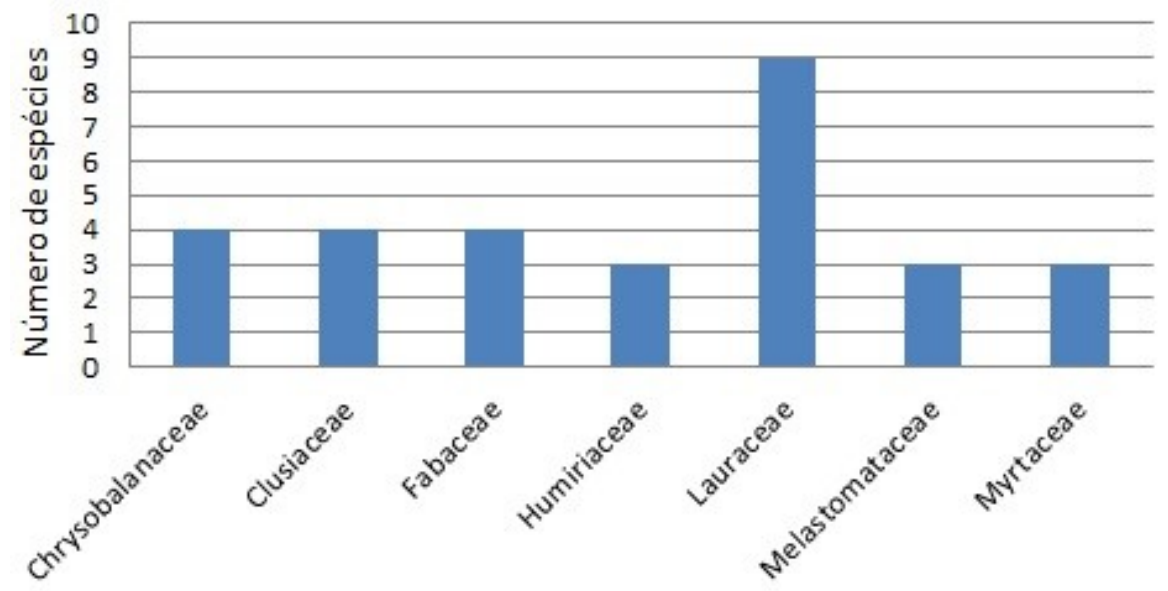

Figura 3: Famílias que apresentaram maior número de espécies na área amostrada.

Muitos gêneros que ocorrem na área de estudo, como Pagamea, Tapirira, Matayba, Ouratea, Myrcia e Cybianthus, assim como algumas espécies, a exemplo de Pagamea coriacea, possuem ampla distribuição no Planalto das Guianas, nos Llanos venezuelanos e colombianos (FERREIRA, 2009; OLIVEIRA et al., 2001), o que sugere um grande input de táxons oriundos destas regiões. Além disso, as famílias Humiriaceae e Xiridaceae, que possuem representantes na área de estudo, possuem, segundo Kubitzki (1990), o centro de distribuição na região das Guianas. No levantamento foi registrada a ocorrência de Eperua purpurea. Segundo Stropp et al. (2011), o gênero Eperua parece ser originado do ecossistema de floresta de terra firme. O gênero Byrsonima, que também foi encontrado na área de estudo, é originado no cerrado (FERREIRA, 2009).

O levantamento florístico da área de estudo sugere uma origem múltipla para flora da região, sendo que a maioria dos táxons é, provavelmente, originária dos Lhanos e Planalto das Guianas. Segundo Stropp (2011) as condições de baixa capacidade de campo, distrofia dos solos e saturação hídrica constante, comuns nas campinas e campinaranas, funcionam como filtros ambientais, selecionando táxos que já possuem adaptações prévias a estas condições. A maioria destes táxons possivelmente começou a colonizar a região após a abertura da drenagem da bacia amazônica para o atlântico, ocorrida a, aproximadamente, 2,5 M.a. pois, anteriormente a este evento, a paisagem da região era caracterizada por ser uma grande área alagada a qual se depositou a Formação Içá 
(CAMPBELL et al., 2006). A abertura da bacia para o leste provocou a reorganização da drenagem, então uma rede de rios e igarapés se formou a partir dos eixos dos rios principais cortando o relevo e dando origem aos baixos platôs, que atualmente constituem os divisores de águas, e drenando as áreas que outrora estiveram alagadas (CAMPBELL et al., 2006; GUIMARÃES, 2014). É possível que algumas espécies adapatadas a condições de saturação hídrica, como Myrcia guianensis, Pagamea coriacea e Hypolitrum schraderianum tenham colonizado algumas áreas mais rasas antes da instalação da rede de drenagem.

Ao longo do transecto, percebeu-se uma substituição gradativa das espécies, indicada pelo Índice de Sörensen, de forma que as parcelas de um mesmo geoambiente, no geral, apresentaram maior similaridade florística. Parcelas de geoambientes diferentes mostraram-se menos similares e quanto maior a distância entre parcelas menor a similaridade. O dendrograma da figura 4 permite melhor análise da similaridade florística entre as parcelas. Nota-se que há a formação de três grupos distintos de parcelas: um contendo as parcelas do geoambiente 4, outro com as parcelas do geoambiente 3, e um terceiro contendo as parcelas dos geoambientes 1 e 2. Este terceiro grupo está dividido em outros três subgrupos, um deles contém uma parcela do G1 (P3) e duas parcelas do G2 (P5 e P6). O agrupamento de parcelas de dois geoambientes distintos (G1 e G2) em um mesmo grupo e subgrupo indica que a similaridade florística entre estes geoambientes é alta. $\mathrm{O}$ isolamento das parcelas do G4 no dendrograma indica uma grande substituição de espécies neste geoambiente, que pode ser interpretada como resultado de mudanças edáficas que serão discutidas mais a diante. Esta acentuada substituição de espécies que ocorre no G4 também fica evidente a partir da CCA (figura 5). Vicentini (2004) também encontrou grande substituição de espécies impulsionadas por mudanças edáficas ao longo de um transecto em estudo sobre campinarana.

Os três primeiros eixos de ordenação da PCA explicaram 70,54\% da variação, sendo que os percentuais de explicação da variação para o $1^{\circ} 2^{\circ}$ e $3^{\circ}$ eixo foram, respectivamente, de $41,44 \%$, $18,82 \%$ e $10,28 \%$. As variáveis mais fortemente relacionadas com o primeiro eixo e que possuem a maior capacidade de explicar a variação ambiental da área estudada foram teores de areia grossa, areia fina, argila e silte, matéria orgânica e P. As variáveis $\mathrm{CTC}, \mathrm{H}+\mathrm{Al}, \mathrm{Al} 3+, \mathrm{Mg}^{2+}, \mathrm{pH}$, nível freático e Mn também foram relevantes para e explicação da variação ambiental por apresentarem autovetores longos e uma forte relação com o primeiro eixo, embora esta relação com o primeiro eixo seja menor do que a apresentada pelas primeiras variáveis citadas (figura 5). As demais variáveis podem ser consideradas "supérfluas" (FELFILI, 2011) para explicar a variação ambiental. 


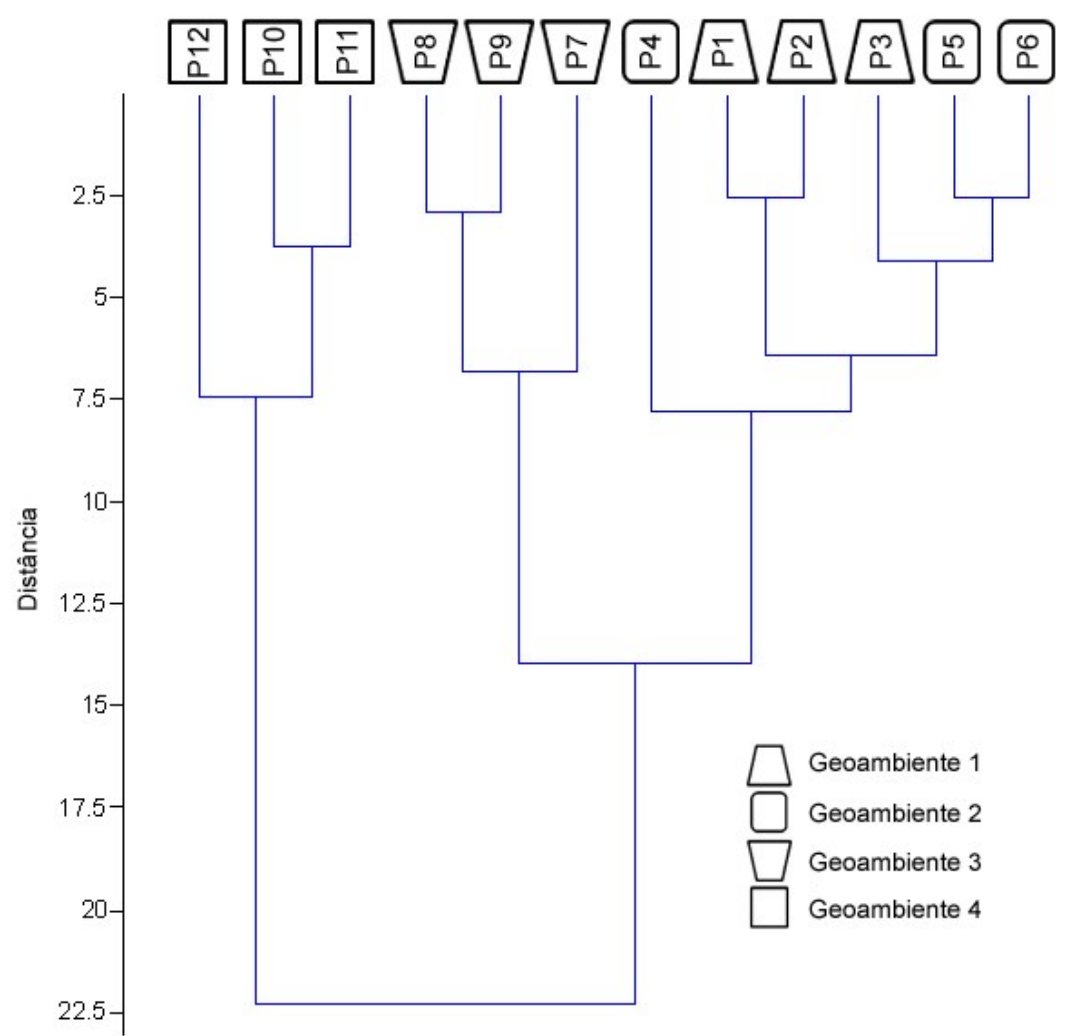

Figura 4: Dendrograma de similaridade florística entre as parcelas.

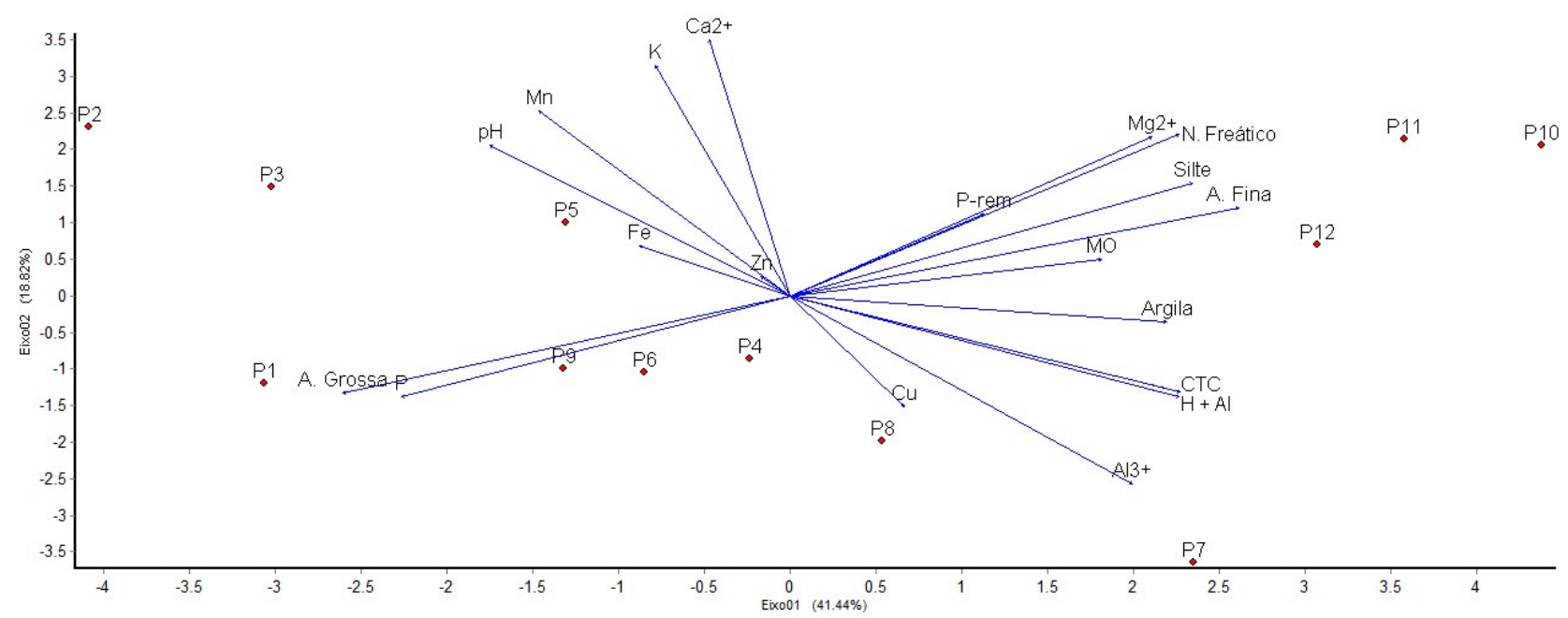

Figura 5: Dois primeiros eixos da análise de componentes principais

Nota-se, no gráfico da figura 5, que as parcelas de um mesmo geoambiente apresentam maior similaridade ambiental, ou seja, menores distância entre os pontos. As parcelas do geoambiente 1 (P1, P2 e P3) e do geoambiete 4 (P10, P11, P12) ocupam posições extremas no eixo 1, o que implica na máxima divergência entre estes geoambientes quanto às características ambientais. A maioria das parcelas dos geoambientes 2 e 3 ocupam posições intermediárias no gráfico. Ao analisar a distância entre as parcelas P4 e P8; P9, P5 e P6, nota-se que há uma pequena distância entre parcelas de geoambientes distintos. Isto significa que as diferenças quanto as características 
ambientais entre os geoambientes 2 e 3 não são tão acentuadas. A exceção reside em P7, que está isolada dos demais pontos. Esta parcela está relacionada a concentrações mais altas de $\mathrm{Al}^{3+}$.

As parcelas do geoambiente 4 estão relacionadas a valores mais elevados de matéria orgânica, areia fina, silte, argila, $\mathrm{Mg}^{2+}, \mathrm{CTC}, \mathrm{H}+\mathrm{Al}$ e nível freático mais alto. Por outro lado, estas unidades amostrais apresentam valores mais baixos de $\mathrm{pH}, \mathrm{Mn}, \mathrm{P}$ e areia grossa. As parcelas do geoambiente 1 apresentam padrão oposto, ou seja, os valores mais elevados das variáveis de $\mathrm{pH}, \mathrm{Mn}, \mathrm{P}$ e areia grossa, e os mais baixos de matéria orgânica, areia fina, silte, argila, $\mathrm{Mg}^{2+}, \mathrm{CTC}, \mathrm{H}+\mathrm{Al}$ e nível freático.

As distâncias entre os pontos que representam as parcelas no biplot gerado pela PCA é concordante com as distâncias geográficas das parcelas ao longo do transecto. Isto quer dizer que, em uma tendência geral apontada pelo modelo, as parcelas de um mesmo geoambiente são mais similares quanto às características ambientais enquanto as parcelas de geoambientes mais distantes (G1 e G4) são os mais dissimilares. Isto indica que na área de estudo há um gradiente ambiental que varia de uma extremidade a outra do transecto.

Os vetores da CTC e da concentração de $\mathrm{H}+\mathrm{Al}$ (figura 5) indicam que estas variáveis apresentam forte relação positiva e estão negativamente relacionadas com o $\mathrm{pH}$. Isto é uma evidência que os sítios de troca catiônicas da matéria orgânica e dos minerais de argila estão quase totalmente ocupados por $\mathrm{H}+\mathrm{Al}$. A relação de diminuição do $\mathrm{pH}$ com o aumento das concentrações de $\mathrm{H}^{+}$e $\mathrm{Al}$ é amplamente conhecida (KIEHL, 1979). Sabe-se que estes elementos são responsáveis pela acidificação do meio de forma direta, no caso do hidrogênio, e indireta, no caso do Al (LINDSAY, 1979; ALLEONI; MELO, 2009). Os cátions básicos do complexo sortivo, como $\mathrm{Ca}^{2+} \mathrm{e}$ $\mathrm{K}^{+}$, ocorrem em pequenas concentrações, possivelmente também adsorvidos às cargas negativas da matéria orgânica e dos minerais de argila. A forte relação da maioria destes elementos com o eixo 2 da PCA pode ser explicada pela pequena variação destes elementos ao longo do transecto, o que teve como consequência a menor importância destas variáveis para a explicação da variação ambiental.

As variáveis que apresentaram maior colinearidade foram: 1. CTC, $\mathrm{H}+\mathrm{Al}$, e $\mathrm{Fe} ; 2 . \mathrm{Al}^{3+}, \mathrm{pH}$, $\mathrm{Mn}$ e $\mathrm{Zn} ; 3$. areia grossa, areia fina e silte e P; 4. Mg2+ e nível do lençol freático e P-rem. De acordo com Dormann et al., (2012) variáveis colineares podem ser reduzidas a apenas um eixo de informação. Assim, para a execução da CCA foram selecionadas variáveis com base na análise dos resultados da PCA. Esta seleção seguiu os critérios de colinearidade e identificação de variáveis com maior poder de explicação da variação. Estas variáveis são: CTC, pH, argila, areia grossa, matéria orgânica, nível freático, $\mathrm{P}, \mathrm{K}, \mathrm{Ca}^{2+} \mathrm{e} \mathrm{Cu}$.

Os três primeiros eixos da CCA explicaram 50.27\% da variação. A análise mostrou que as espécies mais abundantes no G4, Pagamea coriacea, Humiria balsamifera, Chrysochlamys sp., 
Clusia sp. e Adelobotris sp., parecem estar relacionadas com o nível do lençol freático mais alto, maiores teores de $\mathrm{Mg}^{2+}$, silte e areia fina. A importância do nível do lençol freático para a substituição de espécies em ambientes transicionais de campinas e campinaranas foi ressaltada por Ferreira (2009) e Vale (2011). Teores mais elevados de matéria orgânica também parecem estar positivamente relacionados a estas espécies. Por outro lado, a análise mostrou que tais espécies ocorrem onde há menores concentrações de areia grossa (figura 6), o que sugere que esta variável pode ser um fator restritivo para estas espécies. Pagamea coriacea também foi uma espécie importante no estudo de Vale (2011) onde, de forma similar ao presente estudo, se mostrou fortemente relacionada a ambientes com grande saturação hídrica. No entanto, no estudo deste autor, tal espécie se mostrou mais relacionada a solos de textura mais arenosa.

A alta similaridade florística entre as parcelas de G1 e G2, que já havia sido mostrada no dendrograma da figura 4, foi evidenciada pala CCA. Também foi mostrado por esta análise que espécies que apresentaram elevado IVI nestes geoambientes, como Cybianthus fulvopuverulentus, Eugenia patrisii, Licaria martiana e Tapirira retusa podem estar relacionadas a solos mais bem drenados, altas concentrações de areia grossa, P e ao pH mais elevado. Maiores concentrações de K também apresentaram relação positiva com estas espécies, no entanto esta última variável edáfica parece ser menos importante para a ocorrência destas espécies do que as primeiras citadas (figura $6)$.

Quanto às características ambientais edáficas, G2 e G3 poderiam ter sido considerados como apenas um geoambiente (como fica evidente na figura 5). No entanto, considerando a composição florística, observa-se que as parcelas dos geoambientes 1 e 2 apresentaram maior similaridade do que as parcelas dos geoambientes 2 e 3 (figura 4). Se a distribuição das espécies nestes três geoambientes seguisse estritamente um padrão determinístico (teoria dos nichos), o esperado seria que a composição florística fosse mais similar entre os geoambietes 2 e 3, sendo concordante com a similaridade ambiental. Isto sugere que, considerando somente os geoambientes 1, 2 e 3, a maioria das espécies tendem a seguir um padrão de distribuição estocástico (teoria neutra). A ocorrência de vários indivíduos de uma espécie no mesmo geoambiente (restringindo a análise apenas ao G1, G2 e G3), pode significar apenas o efeito de autocorrelação espacial e não que a ocorrência de tal espécie está relacionada a determinada variável ambiental ou com um conjunto de variáveis.

A CCA não mostrou forte relação entre as parcelas e espécies do G3 com nenhuma das variáveis ambientais consideradas no estudo. Notar na figura 6 que os vetores representantes das variáveis ambientais mais próximos a estas parcelas e espécies são CTC e areia grossa. Isto também sugere que as epécies do G3 seguem um padrão de distribuição mais condizente com a teoria neutra do que com a teoria dos nichos e reforça a ideia de que a ocorrência de vários indivíduos da mesma espécie neste geoambiente pode ser resultante da autocorrelação espacial. 


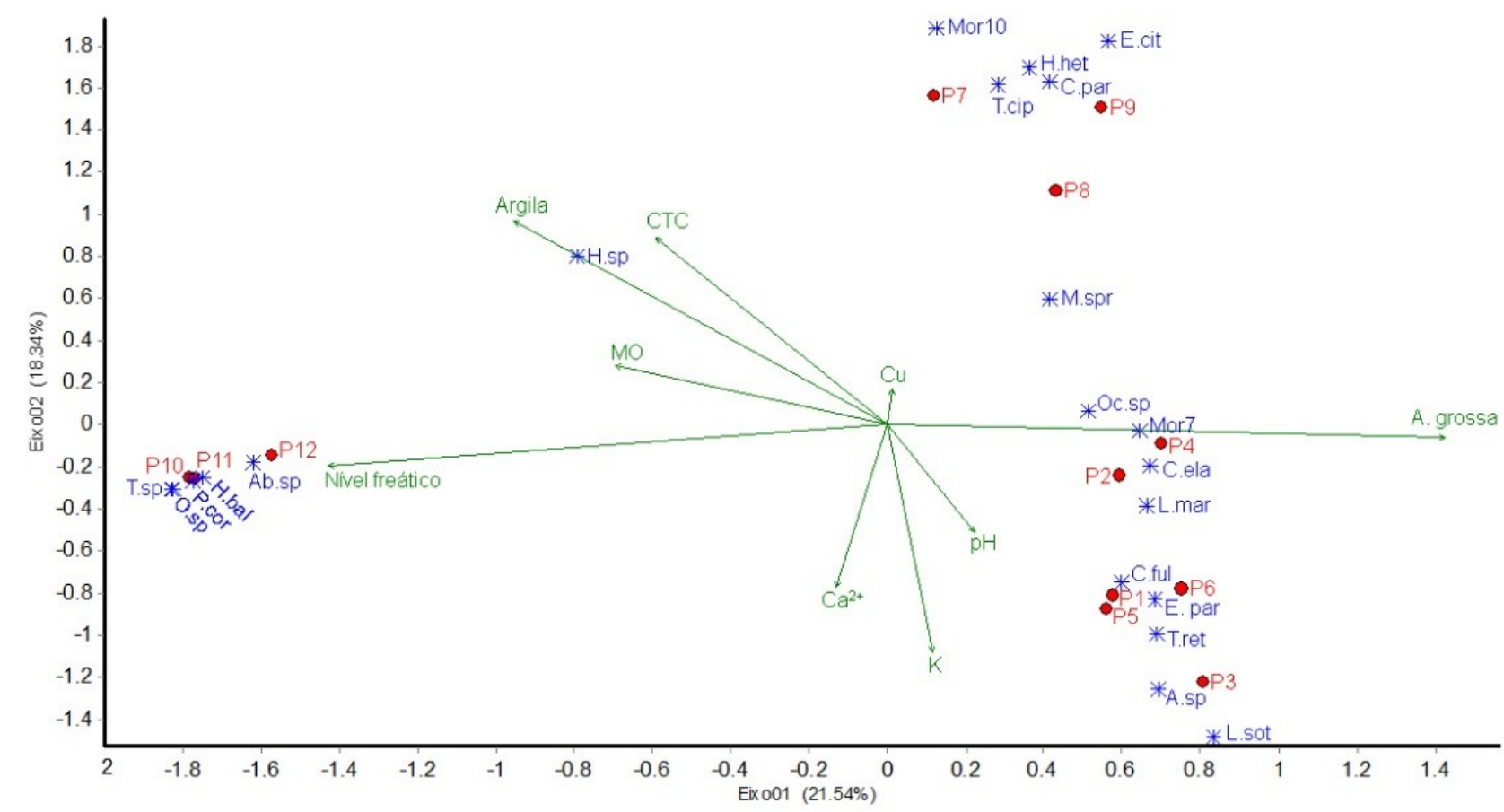

Legenda

$\begin{array}{ll}\text { A.sp } & \text { _Aniba sp. } \\ \text { Ab.sp } & \text { - Adelobotris sp. } \\ \text { C.ela } & \text { - Couepia elata } \\ \text { C.ful } & \text { Cybianthus fulvopuverulentus } \\ \text { C.par } & \text { Couepia parillo } \\ \text { E.cit } & \text { Endlicheria aff citriodora } \\ \text { E.par } & \text { Eugenia patrisii }\end{array}$

\begin{tabular}{|c|c|}
\hline H.bal & _ Humiria balsamifera \\
\hline H.sp & _ humiria Sp. \\
\hline L.het & Licania heteromorpho \\
\hline L.mar & Licaria martiana \\
\hline L.sot & Licania aff Sothersae \\
\hline M.spr & Macoubea sprucei \\
\hline Mor10 & Morfoespecie 10 \\
\hline
\end{tabular}

$\begin{array}{ll}\text { Mor7 } & \text { - Morfoespecie } 7 \\ \text { O.sp } & \text { - Oedematopus sp. } \\ \text { Oc.sp } & \text { - Ocotea sp. } \\ \text { P.cor } & \text { - Pagamea coreacea } \\ \text { T.cip } & \text { - Trichilia cipo } \\ \text { T.ret } & \text { - Tapirira retusa } \\ \text { T.sp } & \text { Tovomitopsis sp. }\end{array}$

Figura 6: Ordenação das variáveis ambientais, variáveis resposta e unidades amostrais em triplot utilizando os eixos 1 e 2 da análise de correspondência canônica.

\subsection{Perfil geoecológico}

Com a análise do perfil geoecológico (figura 7) é possível observar que o número de indivíduos mortos aumenta consideravelmente no G4. As seguintes hipóteses foram levantadas para explicar este fenômeno: 1. o aumento da densidade de indivíduos, o que implica no aumento da competição (RICKLEFS, 2003), considerando que a densidade de indivíduos também aumenta de forma significativa neste geoambiente; 2. o nível freático mais elevado que é tido como uma condição estressante (JACKSON; COLMER, 2005), assim espécies menos adaptadas a estas condições, como algumas que possuem maior importância na campinarana florestada, onde o solo é melhor drenado, podem iniciar seu desenvolvimento nesse geoambiente, mas serem eliminadas rapidamente; 3. pode significar que muitas espécies que apresentam alta frequência na campinarana arborizada possuem ciclo de vida mais curto. O aumento do número de indivíduos ramificados neste geoambiente (figura 7) também pode ser devido ao nível freático elevado, uma vez que em condições de alagamento, uma estratégia adaptativa é o aumento de ramificações no tronco para otimizar trocas gasosas (WITTMANN et al., 2008). 
O índice de diversidade Shannon, calculado para toda a área, apresentou o valor de 3,35. O maior valor do índice de diversidade foi encontrado para o G2. Nota-se que neste geoambiente, o desvio padrão das alturas dos indivíduos é maior (figura 7), o que indica uma maior estratificação, e esta normalmente é relacionada positivamente com a diversidade (RODRIGUES et al., 2009). A diversidade diminuiu em direção ao G4, onde o lençol se encontrava mais próximo à superfície ou até mesmo aflorando em alguns pontos. Possivelmente esta condição de nível freático atua como um filtro ambiental (STROPP, 2011), permitindo que apenas espécies que possuam adaptações a condições de alagamento consigam se estabelecer, favorecendo a dominância de algumas espécies, como foi o caso de Pagamea coriacea e Humiria balsamifera e exclusão de outras, assim explicando a baixa diversidade neste geoambiente.

Em G5 e G6, onde o lençol freático aflora formando um lago raso (figura 8), nota-se que a altura e diâmetro dos indivíduos diminui consideravelmente, assim como a diversidade. Condições de alagamento intensas, como nestes ambientes, diminuem as taxas fotossintéticas (WORBES et al., 1992), resultando na diminuição do aporte de biomassa e, consequentemente, no crescimento dos indivíduos. Uma evidência de que este menor porte pode ser determinado pela saturação hídrica é a ocorrência, em abundância, de Pagamea coriacea, em G4 e G5. No entanto, em G5 a altura e o diâmetro dos indivíduos desta espécie são muito menores.

A curva do teor de matéria orgânica teve comportamento similar às curvas da CTC e do $\mathrm{H}+$ $\mathrm{Al}$, sendo que estas duas últimas ficaram sobrepostas (figura 7). Isto sugere que a matéria orgânica do solo é a principal fonte de sua CTC, o que é esperado para Espodossolos, uma vez que são solos com pequenas quantidades de argila (OLIVEIRA, 2011) que constitui a outra fonte de cargas negativas do solo. A forte relação entre a CTC e o H + Al se deve à ocupação quase total das cargas negativas da matéria orgânica por $\mathrm{H}+\mathrm{Al}$. Esta relação também ficou bem explícita com a PCA (figura 5). A diversidade e altura dos indivíduos diminuíram com o acréscimo da concentração de $\mathrm{H}$ + Al. Já o número de indivíduos mortos aumentou em função do aumento da concentração destes elementos (figura 7).

Os fatores que parecem ter relação mais forte com a diminuição da diversidade e a altura dos indivíduos que ocorrem em direção ao G6 são aumento de $\mathrm{H}+\mathrm{Al}$ e do nível lençol freático, embora, provavelmente, o primeiro seja consequência do segundo, uma vez que o nível freático mais elevado dificulta a decomposição da matéria orgânica, aumentando a CTC do solo, que é ocupada quase totalmente por cátions de $\mathrm{H}^{+}$e $\mathrm{Al}^{3+}$. O decréscimo da diversidade e da altura dos indivíduos em direção ao G6 também pode estar relacionado à diminuição das concentrações de $\mathrm{K}$ e P, como mostra o estudo realizado por Vale (2011). A escassez de nutrientes dos solos os quais as campinaranas se desenvolvem faz com que haja maior investimento em folhas em relação ao 
caule (COOMES e GRUBB, 1996) e defesa contra herbivoria (FINE et al., 2004; FINE et al., 2006), resultando em indivíduos de menor estatura.

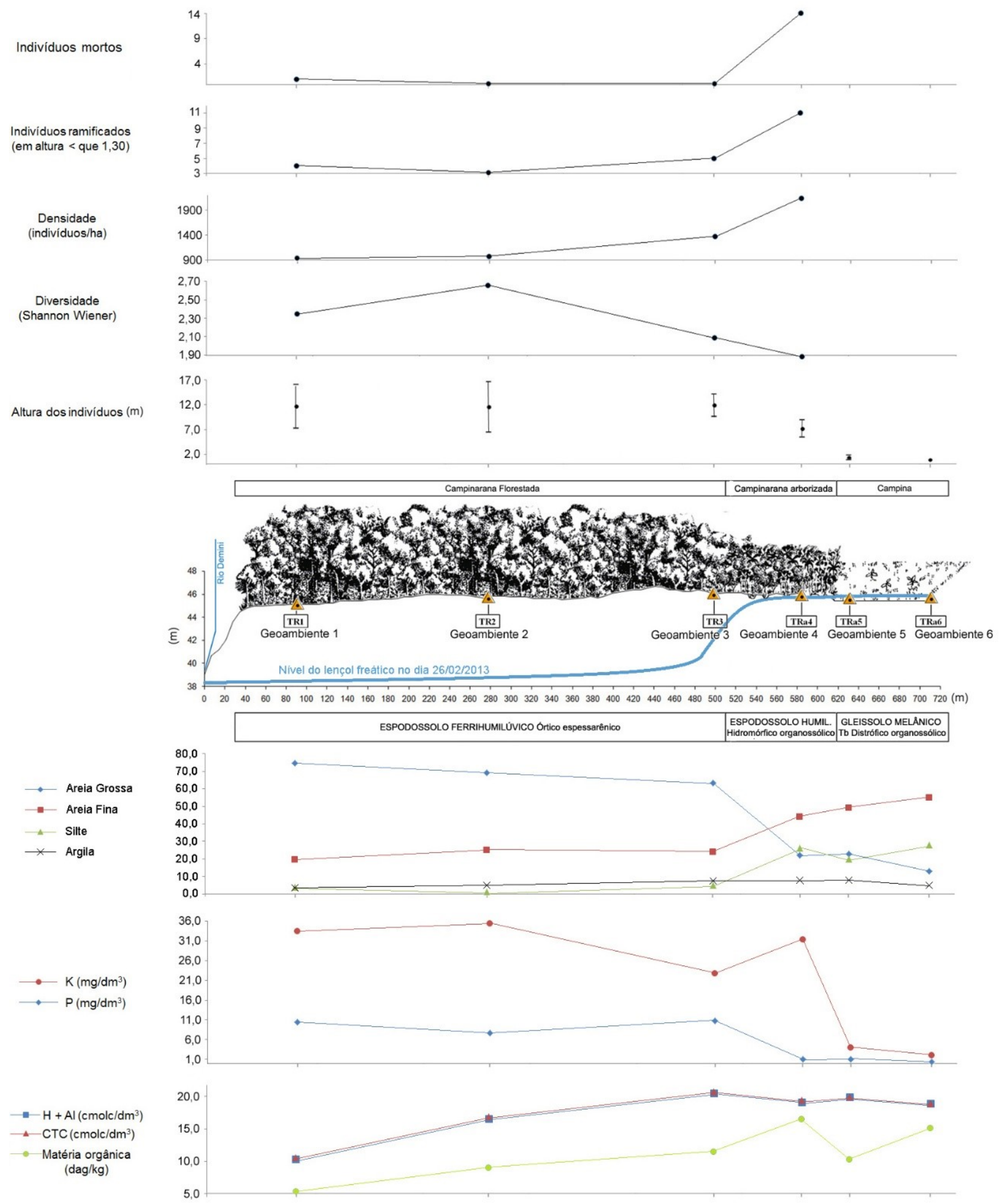

Figura 7: Perfil geoecológico do transecto estudado representando as fitofisionomias campinarana florestada, campinarana arborizada e campina. 


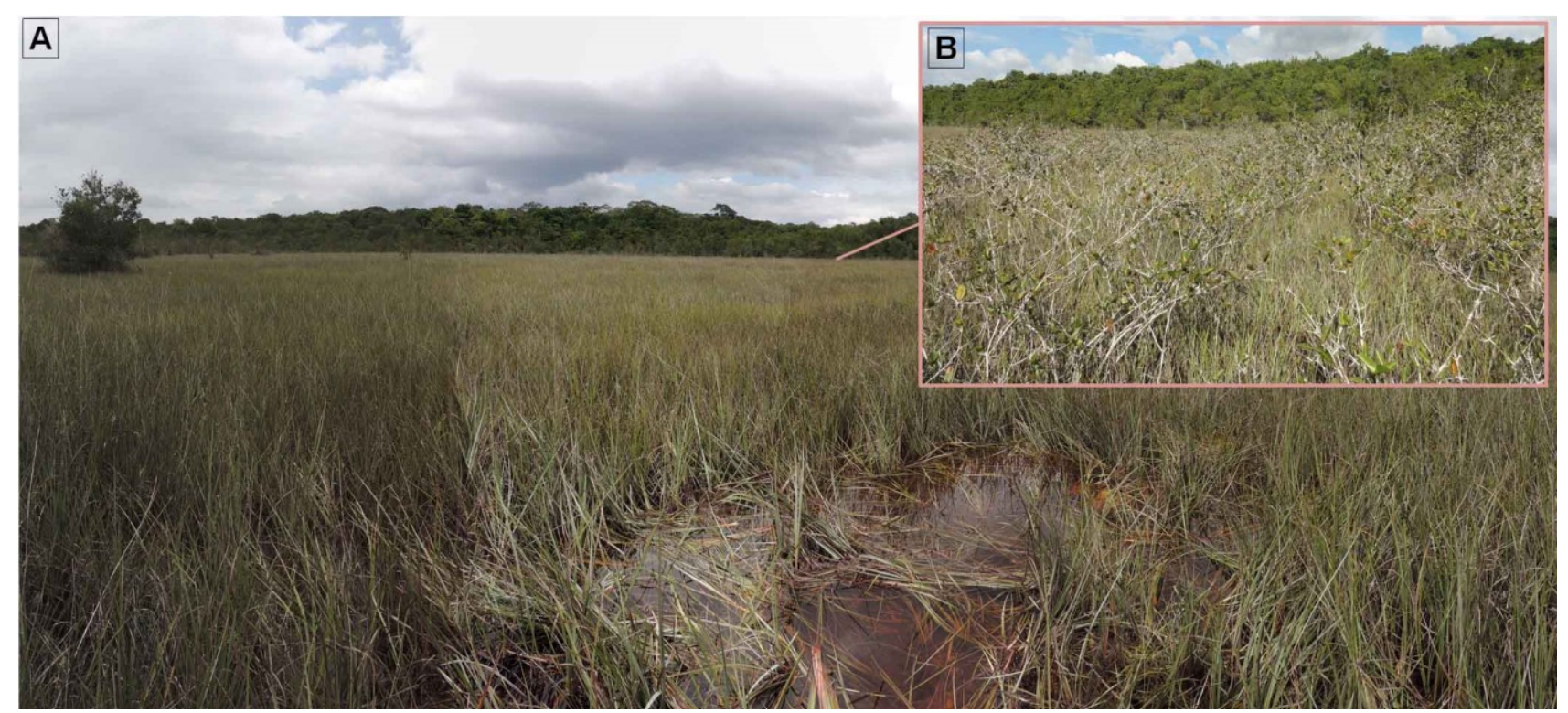

Figura 8:Afloramento do lençol freático e formação de um lago raso no geoambiente 6. O Geoambiente 5, mostrado em B, se encontra próximo a área de campinarana arborizada (G4) e pode ser interpretado como uma transição entre esta fitofisionomia e a campina, uma vez que estes geoambientes apresentam espécies em cumum, a exemplo de Pagamea coriacea. Notar a ocorrência de Hypolitrum schraderianum, formando uma matriz herbácea em ambos geoambientes.

Menores concentrações de $\mathrm{P}$ e $\mathrm{K}$ foram encontradas nos geoambientes com nível freático mais alto e com o aumento dos teores de silte e areia fina. Estes resultados diferem dos encontrados por Vale (2011), onde as maiores concentrações destes nutrientes estão relacionadas com os solos de textura mais fina.

\section{CONSIDERAÇÕES FINAIS}

A flora da região tem origem múltipla apresentando táxons originários do cerrado, floresta de terra firme, e sobretudo dos Lhanos e Planalto das Guianas. Foi identificado uma variação florísitica, estrutural e ambiental ao longo do transecto. O nível do lençol freático e a granulometria foram as variáveis que melhor explicaram a maior parte da variação ambiental ao longo do transecto estudado, o que sugere que as variações florísticas e estruturais são determinadas, sobretudo, por estas variáveis. No entanto, devido ao pequeno esforço amostral contemplado por este estudo, é arriscado assumir posições mais incisivas, principalmente sobre espécies pouco amostradas, acerca de questões como: a distribuição de determinada espécie está relacionada ao aumento ou diminuição de determinadas variáveis ambientais, conforme a teoria dos nichos, ou ocorre de forma aleatória, seguindo a teoria neutra? Quanto da variação florística nestes geoambientes é explicada por fatores ambientais e quanto é explicada pela distância, ou seja, pelo espaço? Para responder com maior segurança a estas questões, sugere-se, em trabalhos futuros, o aumento do esforço amostral e a execução de uma análise de partição de variância. Ressalta-se que 
apesar das limitações em termos de esforço amostral, este estudo pode ser utilizado como um inventário piloto uma vez que estudos florísticos e de Ecologia da vegetação na região são incipientes.

Não foi possível identificar muitos indivíduos até o nível taxonômico de espécie. Isto se deve à dificuldade de coleta de amostras com o material reprodutivo. Para solucionar tal questão seriam necessários vários trabalhos de campo. Não obstante, devido à escassez de estudos florísticos em campinas e campinaranas da região do Rio Demini muitas espécies podem não ter sido ainda descritas.

\section{AGRADECIMENTOS}

A Fundação de Amparo à Pesquisa do Estado de São Paulo (FAPESP) por financiar a pesquisa, à a Fundação de Amparo à Pesquisa do Estado de Minas Gerais (FAPEMIG) pela concessão da bolsa e a equipe de auxiliares de campo.

\section{REFERÊNCIAS}

ALLEONI, L.R.F.; MELO, V.F. (Eds) Química e mineralogia de solos. Volume 1. Viçosa: Sociedade Brasileira de Ciência do Solo, 2009. 695 p.

ANDERSON, A. B. Aspectos florísticos e fitogeográficos de campinas e campinaranas, na Amazônia Central, Manaus. 1978. Dissertação (Mestrado em Ciências Biológicas) - Manaus, AM: INPA/ UFAM.

ANDERSON, A.B. White-sand vegetation of Brazilian Amazonia. Biotropica, v. 13, n. 3, p. 199210. 1981.

BRASIL. Ministério da agricultura. Escritório de meteorologia. Atlas climatológico do Brasil. Rio de Janeiro, 1969

BRASIL. Departamento Nacional da Produção Mineral. Projeto RADAM. Folha NA.20 Boa Vista; geologia e geomorfologia. Rio de Janeiro, 1975 (Série Levantamentos de Recursos Naturais).

BUENO, G.T. Appauvrissement et podzolisation des latérites du baissin du Rio Negro et gênese dês Podzols dans le haut bassin amazonien. 2009 Tese (Doutorado em Geografia) -Rio Claro, SP: UNESP.

CAMPBELl, K. E.; FRAYLEY, C. D.; ROMERO PITTMAN, L. The Pan Amazonian Ucayali Paneplain, late Neogene Sedimentation in Amazonia, and birth of the modern Amazon river system. Palaeogeography, Palaeoclimatology, Palaeoecology v. 239, p. 166-219, 2006.

COOMES, D.A.; GRUBB, P.J. Amazonian caatinga and related communities at

La Esmeralda, Venezuela: forest structure, physiognomy and floristics, and cont-rol by soil factors. Vegetatio n. 122, p. 167-191. 1996. 
CPRM, Companhia de Pesquisa de Recursos Minerais. Programa Levantamentos Geológicos Básicos do Brasil. 2005. Geologia da região da Serra do Imeri. Relatório. p. 70. Disponível em: < http://www.cprm.gov.br/publique/cgi/cgilua.exe/sys/start.htm?infoid $=534 ;$ sid $=26>$. Acesso em 2 jan. 2014.

DALY, D.C.; MITCHELL, J.D. Lowland vegetation of Tropical South America - An Overview, p. 391-454. In: Lentz, D. (Ed.). Imperfect Balance: Landscape transformations in the pre-Columbian Americas. Columbia University Press. 2000.

DORMANN, C. F.; ELITH, J.; BACHER, S; BUCHMANN, C.; CARL, G.; CARRÉ, G.; MARQUÉZ, J. R. G.; GRUBER, B.; LAFOURCADE, B; LEITÃO, P. J.; MÜNKEMÜLLER, T.; MCCLEAN, C.; OSBORNE, P, E.; REINEKING, B; SCHRÖDER, B.; SKIDMORE, A. K.; ZURELL, D; LAUTENBACH, S. 2012. Collinearity: a review of methods to deal with it and a simulation study evaluating their performance. Ecography v. 36, n. 27, p. 27-46, 2012

EMBRAPA SOLOS. Sistema Brasileiro de Classificação de Solos. 3. ed. Rio de Janeiro: Embrapa Informação Tecnológica, 2013. 306 p.

FElfili, J. M.; CARVAlHO, F. A.; LiBANO, A. M.; VENTUROLI, F.; PEREIRA, B. A. S; MACHADO, E. L. M. 2011. Análise multivariada: princípios e métodos em estudos de vegetação, In: FELFILI, J. M EISENLOHR, P. V; MELO, M. M. R. F; ANDRADE. L. A; NETO, J. A. A. M; (Eds.). Fitossociologia no Brasil: métodos e estudos de caso. UFV. Viçosa, Brasil. p. 122-155.

FERREIRA, C. A. C. Análise comparativa de vegetação lenhosa do ecossistema de campina na Amazônia brasileira. 2009. Tese (Doutorado em Biologia Tropical e Recursos Naturais) Manaus, AM: INPA / UFAM.

FINE, P.V.A.; MESONES, I. ; COLEY, P.D. Herbivores Promote Habitat Specialization by Trees in Amazonian Forests. Science, v. 305, n. 5684, p. 663-665. 2004.

FINE, L.V.; MILLER, Z.J.; MESONES, I.; IRAZUZTA, S.; APPEL, H.M.; STEVENS, M.H.H.; SÄÄKSJÄRVI, I.; SCHULTZ, J.C. ; COLEY, P.D. The growth-defense trade-off and habitat specialization by plants in Amazonian forests. Ecology, v. 87, n. 7, p. 150-162. 2006.

GUIMARÃES, F.S. Ecologia e dinâmica vegetal quaternária no contato entre campinarana e campina sobre Espodossolos - Bacia do Rio Demini-AM. 2014. Dissertação (Mestrado em Geografia - Tratamento da Informação Espacial) - Belo Horizonte, MG: PUC-Minas.

JACKSON, M.B.; COLMER, T.D. Response and Adaptation by Plants to Flooding Stress. Annals of Botany, v. 96, n. 4, p. 501-505. 2005.

JUNK, W.J.; PIEDADE, M.T.F.; SCHÖNGART, J.; COHN-HAFT, M.; ADENEY, J.M.; WITTMANN, F. A Classification of Major Naturally-Occurring Amazonian Lowland Wetlands. Wetlands, v. 31, p. 623-640. 2011.

KIEHL, E. J. Manual de edafafologia: relação solo-planta. 1. ed. São Paulo: Ave Maria LTDA, 1979. $262 \mathrm{p}$.

KUBITZKI, K. The ecogeographical differentiation of Amazonia inundation forests. Plant Systematics and Evolution, v. 162, p. 285-304. 1987.

KUBITZKI, K. 1990. The psammonophilous flora of northern South America. Memoirs of the Ne w York Botanical Garden. v. 64, p. 248-253. 1990. 
LEGENDRE. P.; GALLAGHER, E. D. Ecologically meaningful transformations for ordination of species data. Oecologia v. 129, p. 271-280. 2001.

LEVIGHIN, S. C.; VIADANA, A. G. Perfis Geo-ecológicos como técnica para os estudos das condições ambientais. Sociedade ; Natureza, Uberlândia, v. 14 e 15, n. 26 a 29, p. 5-14, 2002/2003.

LINDSAY, W. L. Chemical equilibria in soils. New York: John Wiley and Sons, 1979. 449 p.

MENDONÇA, A. F. M. Campinaranas Amazônicas: pedogênese e relações solo-vegetação. 2011. Tese (Doutorado em Solos e Nutrição de Plantas) - Viçosa, MG: UFV.

MEZZOMO, M. M. Dinâmica da paisagem e a organização das pequenas propriedades rurais em Marechal Cândido Rondon-PR. Geoambiente, n. 11, p. 1-31, 2008.

MEZZOMO, M. M; SANTOS, B. P.; CARNEIRO, M. G. Caracterização física da RPPN Coamo II (Campo Mourão - PR) por meio de perfil geoecológico. Revista Neonorte, v.3, n.4, p. 728-738, 2012.

MULLER-DOMBOIS, D.; ELLENBERG, H. 1974. Aims and methods of vegetation ecology. New York: Wiley; Sons, 1974. 547 p.

NASCIMENTO, N. R.; BUENO, G. T.; FRITSCH, E.; HERBILLON, A.J.; ALLARD, T.; MELFI, A.J.; ASTOLFO, R.; BOUCHER, H. LI, Y. Podzolization as a deferralitization process: a study of an Acrisol-Podzol sequence derived from Palaeozoic sandstones in the northern upper Amazon Basin. European Journal of Soil Science, v. 55, n. 3, p. 523-538, 2004.

OLIVEIRA, J.B. Pedologia Aplicada. 4. ed. Piracicaba: Fealq, 2011. 592 p.

RICKLEFS, Robert E.. A economia da natureza. 5.ed. Rio de Janeiro: Guanabara/Koogan, 2003. $503 \mathrm{p}$.

RODRIGUES, R. R.; BRANCALION, P. H. S.; ISERNHAGEN, I. Pacto pela restauração da mata atlântica: referencial dos conceitos e ações de restauração florestal. São Paulo: LERF/ESALQ, Instituto $\quad$ BioAtlântica, 2009. $256 \quad$ p. 2 Disponível em: $<$ http://www.lerf.esalq.usp.br/divulgacao/produzidos/livros/pacto2009.pdf $>$ Acesso em: $25 \mathrm{dez}$. 2013.

SANTOS, R. D.; LEMOS, R. C.; SANTOS, H. G.; KER, J. C.; ANJOS, L. H. C. Manual de

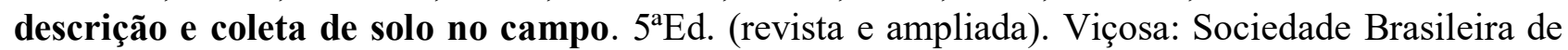
Ciência do Solo, 2005. 100 p.

SILVEIRA, M. 2003. Vegetação e Flora das Campinaranas do Sudoeste Amazônico (JU-008). Relatório de Defesa Técnica, Associação S.O.S. Amazônia, Rio Branco. 28 p.

STROPP, J. Towards an understanding of tree diversity in Amazonian forests. 2011. Tese (Doutorado) - Institute of Environmental Science, Utrecht University.

STROPP, J.; VAN DER SLEEN, P.; ASSUNÇÃO, P. A.; SILVA, A. L. TER STEEGE, H. Tree communities of white-sand and terra-firme forests of the upper Rio Negro. Acta Amazônica.,Manaus. v. 41, n.4. p, 521-544, 2011. Disponível em:

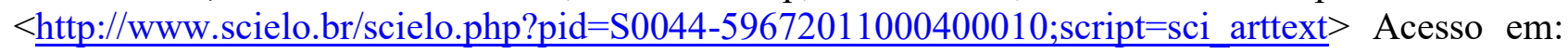
02 mai. 2013. 
TER BRAAK, C. J. F. Canonical correspondence analysis a new eigenvector technique for multivariate direct gradient analysis. Ecology, v.67, p.1167-1179, 1986.

TER BRAAK, C. J. F. the analysis of vegetation-environment relationships by canonical correspondence analysis. Vegetatio, v.69, p. 60-77. 1987.

VALE, G. D. O efeito do solo, inundação e topografia sobre as campinaranas inundáveis na Amazônia. 2011. Dissertação (Mestrado) - Manaus, AM: 2011.

VALENTIN, J, L. Ecologia numérica: uma introdução à análise multivariada de dados ecológicos. 2. ed. Rio de janeiro: Editora Interciência, 2012. 153 p.

VELOSO, H. P.; RANGEL FILHO, A. L. R.; LIMA, J. C. A. Classificação da Vegetação Brasileira, adaptada a um Sistema Universal. Rio de Janeiro: IBGE, 1991. 123 p.

VICENTINI, A. 2004. A Vegetação ao Longo de um Gradiente Edáfico no Parque Nacional do Jaú, p. 117-143. In: Borges, S.H.; IWANAGA, S.; DURIGAN, C.C. ; PINHEIRO, M.R. (Eds.). Janelas para a Biodiversidade no Parque Nacional do Jaú: uma estratégia para o estudo da biodiversidade na Amazônia. Fundação Vitória Amazônica (FVA)/WWF/IBAMA, Manaus, Brasil.

WHITMORE, T.C.; PRANCE, G.T. Biogeography and Quaternary history in tropical America. Clarendon Press, v. 15, n. 6, p. 671-672. 1987.

WITTMANN, F.; ZORZI, B.T.; TIZIANEL, F.A.T.; URQUIZA, M.V.S.; FARIA, R.R.; SOUSA, N.M.; MÓDENA, E.S.; GAMARRA, R.M.; ROSA, A.L.M. Tree Species Composition, Structure and Aboveground Wood Biomass of a Riparian Forest of the Lower Miranda River, Southern Pantanal, Brazil. Folia Geobotanica, v. 43, n. 4. 397-411. 2008.

WORBES, M.; KLINGE, H.; REVILLA, J. D. E.; Martins C. On the dynamics floristic subdivision and geographical distribution of várzea forest in Central Amazonia. Journal of Vegetation Science. v.3, n. 4, 553-564. 1992.

WORBES, M. The Forest Ecossystem of the Floodplains, In: Junk, W.J. The Central Amazon Floodplain: Ecology of a Pulsing System. Ecological Studies, v. 126, p. 223-265. 1997.

Trabalho enviado em 20/10/2016. Trabalho aceito em 04/11/2016. 